Endocrine Care

doi: 10.4183/aeb.2011.69

\title{
SELF-REPORTED DIURNAL PREFERENCE AND SLEEP DISTURBANCE IN TYPE 2 DIABETES MELLITUS
}

\author{
B. Voinescu 1,*, S. Vesa ${ }^{2}$, A. Coogan ${ }^{3}$ \\ 1 "Babes Bolyai" University - Clinical Psychology, Cluj-Napoca, Romania, \\ Clinical County Hospital of Emergency - Psychiatry, Cluj-Napoca, Romania, \\ ${ }^{2}$ Emergency Clinical Hospital - Internal Medicine, Cluj-Napoca, Romania \\ ${ }^{3}$ NUI Maynooth - Psychology, Maynooth, Ireland
}

Abstract

Background. Previous sleep studies suggest that type 2 diabetes mellitus is associated with poor quality of sleep and sleep disorders.

Aim. To evaluate sleep parameters and diurnal preference in type 2 diabetic patients, using a questionnaire.

Methods. Ninety seven patients (aged $55.8 \pm 8.3$, sex ratio $1: 1$ ), previously diagnosed with type 2 diabetes mellitus, together with 102 controls (aged 47.1 \pm 10.5 , sex ratio 1:1), without diabetes, completed a questionnaire containing the Romanian translation of the Composite Scale of Morningness, the Sleep Disorders Questionnaire, the Pittsburgh Sleep Quality Index, the Pittsburgh Insomnia Rating Scale, the Multidimensional Fatigue Inventory, the Epworth Sleepiness Scale, the Alcohol Use Disorders Identification Test and the Beck Depression Inventory II (BDI). The study was cross-sectional, as we included subjects from outpatient and inpatient facilities. The recruitment process was based on handing invitation letters to patients consulting their physician, as well as to their acquaintances, using the snowball sampling. Participation was voluntary and anonymous.
Results. Insomnia was more often reported in diabetic patients: $32(33.0 \%)$ vs. $16(15.7 \%)$ controls, a difference that was highly significant $(\mathrm{P}<0.001)$. Diabetic patients used to wake up at approximately the same hour as controls did; nevertheless they went to bed earlier (22:14 \pm 0:57 vs. $22: 32 \pm 1: 03)$, needed more minutes to fall asleep $(28.84 \pm 21.01$ vs. $24.32 \pm 23.45)$ and slept less than controls $(7.01 \pm 1.56$ vs. 7.23 \pm 1.18 ). Statistically significant differences between patients and controls were found regarding the Pittsburgh Sleep Quality Index $(\mathrm{P}=0.005)$, the Pittsburgh Insomnia Rating Scale $(\mathrm{P}<0.001)$ and the Multidimensional Fatigue Inventory $(\mathrm{P}=0.001)$ scores. Eighteen $(18.5 \%)$ patients also met the criteria for a depressive disorder. No significant differences between patients and controls were found as related to their chronotype $(\mathrm{P}=0.32)$

Conclusion. Poor sleep, but not diurnal preference, was linked with the presence of type 2 diabetes mellitus.

Key words: sleep , insomnia , diurnal preference, self-reports, circadian rhythms, type 2 diabetes mellitus.

*Correspondence to: Bogdan Voinescu, Babes Bolyai University - Clinical Psychology, Republicii

47 Cluj-Napoca 400015, Romania, Email: bogdan.voinescu@gmail.com

Acta Endocrinologica (Buc), vol. VII, no. 1, p. 69-82, 2011 


\section{INTRODUCTION}

Considerable epidemiological evidence shows that life-style changes impairing sleep have effects on our circadian rhythms with metabolic consequences $(1,2)$. These findings are in line with increasing evidence demonstrating that the organization of metabolism is a key function of circadian systems (3). Prospective studies from different geographic regions, that explored the relationship between sleep duration and/or quality and diabetes, have indicated that short or poor sleep may increase the risk of developing type 2 diabetes, the association being stronger in women (4). Among the hypotheses attached to these observations is that alteration of sleep homeostasis impacts on metabolism (for reviews see 1,2) with sleep disorders, particularly insomnia, appearing to have important and negative consequences (57). Diabetes itself is also associated with complications and symptoms, such as neuropathic pain, nocturia and depression, that may contribute to sleep disorders, although sleep disruptions also occur frequently in diabetic patients without complications or obesity (1).

Sleep quality and efficacy, as well as circadian parameters, can be measured objectively with polysomnography, actigraphy and endocrine measures, but these methods are not suitable for all situations due to their demands on study participants. Validated self-report questionnaires assess phenomena that are currently impossible to measure objectively with current technologies and are commonly used, being both inexpensive and convenient. With no easily accessible biomarkers of insomnia, such tools play an important research role (8). Diurnal preference (i.e. whether a subject is morning or evening oriented) is a parameter that is correlated with biological markers of circadian rhythmicity, and can be assessed in subjects by a number of validated questionnaires, such as the Composite Scale of Morningness (9).

\section{Purpose of this study}

To evaluate sleep parameters and diurnal preference in type 2 diabetic patients in a cross-sectional study. We hypothesized that sleep disruptions are more severe in patients compared to controls and that they might be under the influence of clinical variables and of the diurnal preference.

\section{SUBJECTS AND METHODS}

\section{Participants}

Patients were recruited randomly from outpatient and inpatient facilities at Baia Mare County Hospital, Romania from January till July in 2009. All patients had their diagnosis of type 2 diabetes mellitus confirmed by a specialist, based on WHO guidelines. Volunteering control subjects, aged over 30, were recruited from patients' families or acquaintances.

Exclusion criteria were pregnancy and known co-morbid conditions, such as cardiac (severe heart failure, unstable angina), dermatologic (psoriasis), gastrointestinal (inflammatory bowel disease), neurologic (stroke, Parkinson disease, epilepsy, traumatic brain injury), pulmonary (obstructive sleep apnoea, persistent asthma, chronic obstructive pulmonary disease), psychiatric (chronic 
or acute psychosis, bipolar disorder, dementia, mental retardation), endocrine (hypo- or hyperthyroidism) diseases. The study was approved by the Ethics Committee of "Iuliu Hatieganu" Medicine and Pharmacy University, Cluj-Napoca, Romania.

\section{Instruments}

A questionnaire containing the Romanian translation of the Composite Scale of Morningness (9), the Sleep Disturbance Questionnaire (10), the Pittsburgh Insomnia Rating Scale (11), the Pittsburgh Sleep Quality Index (12), the Epworth Sleepiness Scale (13), the Multidimensional Fatigue Inventory (14), the Alcohol Use Disorders Identification Test (15) and the Beck Depression Inventory II (BDI) (16), as well as demographic and clinical data, were used. The first three mentioned instruments were translated and partially validated by ourselves (17), while the rest have already been used by other Romanian investigators.

The Composite Scale of Morningness (CSM) contains 13 questions, most of them having four choices, with a Likert-type response format and total scores range from 13 (extreme eveningness) to 55 (extreme morningness) (9). Although its authors proposed a three-category typology, based on the $10^{\text {th }}$ and $90^{\text {th }}$ percentile, we used the cut-off scores determined by age groups on the $25^{\text {th }}$ and $75^{\text {th }}$ percentiles that were determined in a Romanian sample (18).

The Sleep Disturbance Questionnaire (SDQ) is a self-rating questionnaire with 18 questions on different sleep problems. The first group of questions asks the subject to evaluate the presence of insomnia, excessive sleepiness, sleep apnoea and parasomnias in the last month.
A subsequent set of questions investigates the duration, frequency and consequences of the problem, and is used for the evaluation of the severity of the sleep disturbances reported. The SDQ divides the subjects into three main categories: subjects who do not complain of any sleep disorder, subjects who report the occurrence of insomnia problems without satisfying the DSM-IV and ICSD criteria and subjects whose symptoms meet DSMIV and ICSD criteria for insomnia (10).

The Pittsburgh Sleep Quality Index (PSQI) is a widely used, self-rated, 18item questionnaire that generates seven component scores, ranging from subscale scores 0 to 3: sleep quality, sleep latency, sleep duration, habitual sleep efficiency, sleep disturbances, use of sleep medications and daytime dysfunction. The global score ranges from 0 to 21 ; a higher score is indicative of poorer subjective sleep quality (12). Used together with the PSQI, the Epworth Sleepiness Scale (ESS) is a simple, selfadministered questionnaire that provides a measurement of the subject's general level of daytime sleepiness. It rates the chances that the subject would doze off or fall asleep when in eight different situations commonly encountered in daily life (13).

The Pittsburgh Insomnia Rating Scale (PIRS) is a 65-item scale designed to rate the severity of insomnia in clinical trials. Subjects rate items that ask about subjective distress (46 items), subjective sleep parameters (10 items) and quality-of-life (9 items) in the past week. This scale is still under development, but preliminary data indicated that the PIRS had good testretest reliability as a measure of 
insomnia severity in the past week. It appeared to have good concurrent validity with the PSQI (11).

The Multidimensional Fatigue Inventory (MFI) is a 20-item self-report instrument designed to measure fatigue. It covers the following dimensions: general fatigue, physical fatigue, mental fatigue, reduced motivation and reduced activity. General fatigue includes general statements concerning a person's functional state. Physical fatigue refers to the physical sensation related to the feeling of tiredness. Possible somatic symptoms of fatigue such as lightheadedness or muscle pain are not included in this scale in order to minimize contamination with symptoms of somatic illness, independent of fatigue. Cognitive symptoms such as having difficulties concentrating are included in the scales for mental fatigue. Reduced activities and reduced motivation cover reduction in activities and lack of motivation to start any activity (14).

The Alcohol Use Disorders Identification Test (AUDIT) scale is one of the brief instruments available for measuring the prevalence of hazardous drinking, both in clinical and student populations. It consists of 10 items. Except for the last two items, AUDIT questions hint at the previous year, and responses are weighted between 0 and 4 , generally based on frequency of occurrence (19).

The Beck Depression Inventory II is a widely used instrument for measuring the severity of depression. It is composed of 21 items relating to symptoms of depression, each of which consists of four self-evaluative statements scored 0 to 3 . Responses are summed to yield a total score that ranges from 0 to 63 (16).

\section{Procedure}

Participation was voluntary and anonymous. Diabetic patients, not meeting the exclusion criteria, received an invitation letter from their GP or specialist. The letter explained the nature of research and ethical requirements for confidentiality. If agreed, they were given the questionnaires to be completed. All the participants were also asked to further recruit adult participants from their acquaintances using the snowball sampling. Completing the survey was considered implied consent to participate in this study. We did not count how many questionnaires had been handed.

\section{Statistical analysis}

Total scores are expressed as means, standard deviations, medians and 25 and 75 percentiles. Distribution shapes were assessed for normality with the Kolmogorov-Smirnov test. The reliability of the scales was estimated by Cronbach's $\alpha$ coefficients. To examine the statistical significance of the differences, the Mann-Whitney U test was used. To evaluate the distribution of various characteristics, Chi Square test was used. Kendall's tau b was used for calculating correlations between the different variables. A P value, lower than 0.05 , was considered significant. Data analysis was performed using the SPSS (version 16.0.2).

\section{RESULTS}

\section{Descriptive statistics}

Ninety seven patients and one hundred and two controls were selected 
for this study. About half of the patients were men $(\mathrm{N}=49 ; 50.5 \%)$. Most of the controls were women $(\mathrm{N}=53 ; 52.0 \%)$. Controls were younger than patients: mean age was $55.85 \pm 8.30$ in the patients' sample and $47.16 \pm 10.53$ in the controls' one. Five subjects did not fill their ages. Age was not normally distributed and the difference between the groups was highly significant $(\mathrm{P}<0.001)$.

The mean body mass index (BMI) in the patients group was $30.21 \pm 6.24$ and $25.49 \pm 4.44$ in the control group. Six subjects did not fill their height and weight, therefore BMI was not calculated. This difference in BMI between the diabetic and control groups was highly significant $(\mathrm{P}<0.001)$. About half of the patients (43; $47.7 \%$ ) were obese (BMI $\geq 30$ ) compared to eleven $(10.9 \%)$ of the controls, and this difference was highly significant (Chi square test, $\mathrm{P}<0.001$ ). Neither neuropathy, nor peripheral arterial disease was reported by the selected individuals.

The majority of diabetic patients complained of insomnia: 55 (56.7\%) as a symptom, while $32(33.0 \%)$ fulfilled the criteria of insomnia as a disease. Controls had less primary sleep disturbance, with $65(63.7 \%)$ of controls displaying insomnia symptoms, but only $16(15.7 \%)$ insomnia as a disease. Ten patients $(10.3 \%)$ and 21 (20.6\%) controls had no insomnia complaints at all. These differences were highly significant (Chi square test, $\mathrm{P}<0.001)$. We found no important differences in alcohol use or smoking before going to sleep, as well as in snoring, breathing difficulties or pain during the night (details of the above in Table 1). However, patients had nocturia significantly more frequently $(\mathrm{P}=0.026)$.

Table 1. Demographic, clinical, and sleep characteristics of the study population

\begin{tabular}{lll}
\hline & Diabetes & Controls \\
\hline Age* (years) & $55.85 \pm 8.30$ & $47.16 \pm 10.53$ \\
BMI* & $30.21 \pm 6.24$ & $25.49 \pm 4.44$ \\
BMI percentile & & \\
$25^{\text {th }}$ & 25.88 & 22.06 \\
$50^{\text {th }}$ & 29.75 & 25.15 \\
$75^{\text {th }}$ & 32.96 & 28.01 \\
Obesity (BMI $\left.>30 \mathrm{~kg} / \mathrm{m}^{2}\right)(\%)$ & 46.7 & 10.9 \\
Sex $(\%$ male) & 50.5 & 48.0 \\
Current smoker $(\%)$ & 23.3 & 25.5 \\
Current alcohol consumption** (\%) & 38.5 & 20.2 \\
Snoring (\%) & 36.7 & 28.4 \\
Breathing problems $(\%)$ & 11.3 & 7.8 \\
Depression $(\%)$ & 18.5 & 0 \\
Sleep difficulty $(\%)$ & & \\
Normal sleeping & 10.3 & 20.6 \\
Poor sleeping & 56.7 & 63.7 \\
Insomnia & 33.0 & 15.7 \\
* means and standard deviations & \\
** moderate and high consumption as revealed by AUDIT
\end{tabular}


About half of the patients (49) were using insulin for the treatment of their disease. We found that they had significantly more frequent sleep disturbances $(\mathrm{P}=0.032)$ and obesity $(\mathrm{P}=0.02)$ compared to those patients who were not using insulin.

\section{Psychometric Scales}

A summary of the median scores in the used scales, together with $25^{\text {th }}$ and 75th percentiles, range, $\alpha$ Cronbach's coefficients and $\mathrm{P}$ values in the Mann-Whitney U-test are presented in Table 2.

\section{Pittsburgh Sleep Quality Index}

Diabetic patients reported fairly similar waking up times as controls did, but they went to bed earlier, needed more minutes to fall asleep, slept less and spent more hours in bed, as it can be seen in Table 3.

Patients complained of significantly more severe sleep disruptions $(\mathrm{P}=0.03)$, reported more time to fall asleep $(\mathrm{P}=0.009)$, had a less efficient sleep $(\mathrm{P}=0.007)$ and of a poorer quality $(\mathrm{P}=0.03)$; they also used sleep medications more frequently than controls $(\mathrm{P}=0.001)$. Obesity was not significantly associated with PSQI scores higher than 5 , as obese and non-obese patients were almost equally distributed.

Among other differences between the groups, diabetic patients complained significantly more often of feeling too warm or cold during the night and of nocturia, but not of pains, as revealed in Table 4.

Sixty seven $(69.1 \%)$ patients scored higher than 5, the cut-off score for bad sleepers. Twenty three (44.2\%) of them had insomnia as a disease and twenty nine (55.8\%) insomnia as a symptom. Male patients reported worse sleep quality than women, but the differences were not significant. Patients with insomnia as a disease scored higher than those with insomnia as a symptom and the difference was significant $(\mathrm{P}=0.066)$. Thirty five controls $(34.3 \%)$ scored higher than 5 in PSQI. Twenty one $(20.6 \%)$ had no insomnia complaints, while $65(63.7 \%)$ had insomnia symptoms and $16(15.7 \%)$ insomnia as a disease.

\section{Pittsburgh Insomnia Rating Scale}

Diabetic patients scored significantly higher in this scale and its subscales, reflecting that they reported more severe sleep disruptions and worse quality of life (see Table 5). The PIRS scores were highly significantly related to the total PSQI ones $(\tau=0.335$, $\mathrm{P}<0.001)$. The PIRS subscales were highly significantly related to the total PSQI scores, particularly the Sleep Parameters $(\tau=0.424, \mathrm{P}<0.001)$ and the Quality of Life one $(\tau=0.396, \mathrm{P}<0.001)$.

\section{Multidimensional Fatigue Inventory}

Patients displayed higher levels of fatigue and significant differences in mental and activity subscales (as seen in Table 5). MFI scores were lowly correlated with the PSQI $(\tau=0.192$, $\mathrm{P}<0.001)$ and correlated with a medium strength with PIRS $(\tau=0.329, \mathrm{P}<0.001)$.

\section{Epworth Sleepiness Scale}

Diabetic patients complained slightly more often of daytime sleepiness, but the significance did not reach the 0.05 level. Twenty six (29.21\%) of the patients scored higher than 10 , compared to $21(24.13 \%)$ of the 
Table 2. Summary of the descriptive statistics and reliability for the scales used ( $\alpha$ Cronbach is calculated for the whole sample). Last column is for the $\mathrm{P}$ values in Mann-Whitney U test (significant values are in bold)

\begin{tabular}{|c|c|c|c|c|}
\hline PSQI & $\begin{array}{l}\text { Median } \\
75 \text { percentile } \\
25 \text { percentile } \\
\text { Range } \\
\text { a Cronbach }\end{array}$ & $\begin{array}{l}\text { Patients (N=90) } \\
6.5 \\
9.0 \\
4.0 \\
2-16 \\
0.797\end{array}$ & $\begin{array}{l}\text { Controls }(\mathrm{N}=\mathbf{8 7}) \\
5 \\
7 \\
5 \\
2-14\end{array}$ & $\begin{array}{l}\mathrm{P} \\
0.005\end{array}$ \\
\hline PIRS & $\begin{array}{l}\text { Median } \\
75 \text { percentile } \\
25 \text { percentile } \\
\text { Range } \\
\text { a Cronbach }\end{array}$ & $\begin{array}{l}\text { Patients (N=87) } \\
82 \\
101 \\
64 \\
15-170 \\
0.97\end{array}$ & $\begin{array}{l}\text { Controls }(\mathbf{N}=\mathbf{8 5}) \\
49 \\
78.5 \\
27 \\
2-128\end{array}$ & $<0.001$ \\
\hline ESS & $\begin{array}{l}\text { Median } \\
75 \text { percentile } \\
25 \text { percentile } \\
\text { Range } \\
\text { a Cronbach }\end{array}$ & $\begin{array}{l}\text { Patients (N=89) } \\
8 \\
11 \\
6 \\
1-20 \\
0.687\end{array}$ & $\begin{array}{l}\text { Controls }(N=87) \\
8 \\
10 \\
4 \\
0-16\end{array}$ & 0.08 \\
\hline MFI & $\begin{array}{l}\text { Median } \\
75 \text { percentile } \\
25 \text { percentile } \\
\text { Range } \\
\text { a Cronbach }\end{array}$ & $\begin{array}{l}\text { Patients (N=89) } \\
58 \\
64 \\
49 \\
20-92 \\
0.880\end{array}$ & $\begin{array}{l}\text { Controls }(\mathbf{N}=\mathbf{8 6}) \\
52.5 \\
60 \\
39.75 \\
23-97\end{array}$ & 0.011 \\
\hline BDI II & $\begin{array}{l}\text { Median } \\
75 \text { percentile } \\
25 \text { percentile } \\
\text { Range } \\
\text { a Cronbach }\end{array}$ & $\begin{array}{l}\text { Patients (N=97) } \\
0 \\
15 \\
0 \\
5-58 \\
0.916 \\
\end{array}$ & $\begin{array}{l}\text { Controls }(\mathrm{N}=\mathbf{1 0 2}) \\
0 \\
8.25 \\
0 \\
0-32\end{array}$ & 0.20 \\
\hline AUDIT & $\begin{array}{l}\text { Median } \\
75 \text { percentile } \\
25 \text { percentile } \\
\text { Range } \\
\text { a Cronbach }\end{array}$ & $\begin{array}{l}\text { Patients (N=97) } \\
1 \\
4.5 \\
0 \\
1-26 \\
0.915\end{array}$ & $\begin{array}{l}\text { Controls }(\mathrm{N}=\mathbf{1 0 2}) \\
1 \\
3 \\
0 \\
1-35\end{array}$ & 0.30 \\
\hline CSM & $\begin{array}{l}\text { Median } \\
75 \text { percentile } \\
25 \text { percentile } \\
\text { Range } \\
\text { a Cronbach }\end{array}$ & $\begin{array}{l}\text { Patients (N=97) } \\
41 \\
44 \\
39 \\
23-51 \\
0.797\end{array}$ & $\begin{array}{l}\text { Controls (N=102) } \\
42 \\
45 \\
37 \\
20-54\end{array}$ & 0.70 \\
\hline
\end{tabular}


Table 3. Means and SDs for sleep parameters in patients and controls

\begin{tabular}{lll}
\hline PSQI Parameter & Patients & Controls \\
\hline Waking Up Time & $6: 35 \pm 0: 59$ & $6: 35 \pm 1: 25$ \\
Going to Bed Time & $22: 14 \pm 0: 57$ & $22: 32 \pm 1: 03$ \\
Minutes Needed for Falling & $28.84 \pm 21.01$ & $24.32 \pm 23.45$ \\
Asleep & & \\
Hours of Sleep & $7.01 \pm 1.56$ & $7.23 \pm 1.18$ \\
Hours Spent in Bed & $8.35 \pm 1.30$ & $7.74 \pm 1.25$ \\
\hline
\end{tabular}

Table 4. Sleep difficulties and their frequency; last column is the Pearson Chi-Square

\begin{tabular}{|c|c|c|c|c|}
\hline & Frequency & Patients & Controls & $\mathrm{P}$ \\
\hline \multirow{4}{*}{$\begin{array}{l}\text { Had to use the } \\
\text { bathroom }\end{array}$} & Not during the past month & 13 & 16 & \\
\hline & Less than once a week & 11 & 25 & \\
\hline & Once or twice a week & 26 & 25 & 0.026 \\
\hline & Three or more times a week & 40 & 25 & \\
\hline \multirow{4}{*}{ Felt too cold } & Not during the past month & 58 & 72 & \\
\hline & Less than once a week & 19 & 10 & \\
\hline & Once or twice a week & 3 & 9 & 0.001 \\
\hline & Three or more times a week & 10 & 0 & \\
\hline \multirow[t]{4}{*}{ Felt too hot } & Not during the past month & 42 & 61 & \\
\hline & Less than once a week & 16 & 15 & \\
\hline & Once or twice a week & 14 & 10 & 0.009 \\
\hline & Three or more times a week & 18 & 5 & \\
\hline \multirow[t]{4}{*}{ Had pains } & Not during the past month & 44 & 57 & \\
\hline & Less than once a week & 15 & 13 & \\
\hline & Once or twice a week & 18 & 9 & 0.183 \\
\hline & Three or more times a week & 13 & 12 & \\
\hline
\end{tabular}

controls and this difference was not significant. Scores in ESS were either not significantly, or poorly, correlated with the other scales: $\tau=0.061(\mathrm{P}=0.13)$ with PSQI, $\tau=0.136(\mathrm{P}=0.005)$ with PIRS, $\tau=0.076(\mathrm{P}=0.077)$ with MFI.

\section{Beck Depression Inventory II}

From the subjects that completed the BDI, patients did score higher than the controls and the differences were significant. Eighteen (18.5\%) patients met the criteria for current depressive disorder. According to BDI cut-off scores, 7 (7.2\%) of the patients had severe depression, while $8(8.24 \%)$ had moderate one. Compared to controls, the differences were highly significant $(\mathrm{P}<0.001)$. The BDI scores were highly significantly related to the PIRS ones $(\tau=0.472$, $\mathrm{P}<0.001)$ and PSQI $(\tau=0.327, \mathrm{P}=0.001)$, and poorly to the Epworth $(\tau=0.206$, $\mathrm{P}=0.005)$ and the MFI ones $(\tau=0.180$, 
Table 5. Medians and 25/75 percentiles for the scores in PIRS and MFI subscales in patients and controls, together with Mann-Whitney U-test results

\begin{tabular}{lllllllll}
\hline & \multicolumn{9}{c}{ Patients } & \multicolumn{7}{c}{ Controls } & P \\
\hline $\begin{array}{l}\text { Percentile } \\
\text { PIRS }\end{array}$ & 25 & 50 & 75 & 25 & 50 & 75 & \\
Sleep distress & 44 & 61 & 76 & 13.5 & 34 & 56.5 & $<0.001$ \\
Sleep parameters & 7 & 9 & 12 & 3 & 7 & 10 & $<0.001$ \\
Quality of life & 9 & 12 & 14 & 7 & 9 & 12 & 0.001 \\
MFI & & & & & & & \\
General fatigue & 10 & 12 & 14 & 9 & 11 & 13 & 0.180 \\
Activity fatigue & 10 & 11 & 14 & 7 & 10 & 13 & 0.013 \\
Physical fatigue & 8 & 11 & 14 & 8.75 & 10.5 & 13 & 0.274 \\
Motivation fatigue & 8 & 10 & 12 & 6 & 8.5 & 12 & 0.077 \\
Mental fatigue & 9.5 & 11 & 13 & 6.75 & 9.5 & 12 & 0.004 \\
\hline
\end{tabular}

$\mathrm{P}=0.016)$. Of the patients who completed the scale, only one $(2.85 \%)$ had no insomnia symptoms and $24(68.5 \%)$ were bad sleepers according to PSQI.

\section{Alcohol Use Disorders Identification Test}

In this scale, the patients did score higher than the controls again; however, the differences were not significant. The AUDIT scores were significantly, but poorly related to the PIRS $(\tau=0.115$, $\mathrm{P}=0.045)$, the MFI $(\tau=0.226, \mathrm{P}<0.001)$ and the Epworth ones $(\tau=0.230$, $\mathrm{P}<0.001)$. No association between chronotype, insomnia accuses or severity of depression (according to BDI) and alcohol consumption were found, but we did find one between bad sleepers (according to PSQI) $(\mathrm{P}<0.001)$.

\section{Composite Scale of Morningness}

The median of the total CSM score for the patients group was 41, in both men and women; in controls median was 43 in men and 39 in women. CSM scores did not correlate to the other variables. There were no significant differences between those affected by diabetes and those unaffected in their diurnal preference $(\mathrm{P}=0.32)$. Although evening types appeared to be bad sleepers more frequently, no difference was found in the distribution, using the percentiles rules $(\mathrm{P}=0.826)$. Morning types complained of slightly more fatigue, but the differences were not significant. Most of the patients that had depression $(\mathrm{N}=15 ; 45.45 \%)$ were of the evening type and the difference was significant $(\mathrm{P}=0.011)$.

\section{DISCUSSION}

This study attempts to assess both the quality of sleep and the consequences of loss of sleep in diabetic patients compared to controls and to explore the relationship between diurnal preference and type 2 diabetes mellitus. About two hundred participants were selected for 


\section{B. Voinescu et al.}

this research and were self-assessed with validated translated instruments that displayed similar psychometric properties to the original ones. Sex distribution was almost similar among the two compared groups, but the patients' group was older.

The sleep-wake cycle is one of the most obvious patterns in human behavior and physiology and it is believed to be intimately involved in the onset and during the course of diabetes (1, 2, 5-7, 20-22). Moreover, shift work or fragmented working hours have been associated with increased risk for obesity, diabetes, and cardiovascular disease, with recent results showing that in healthy people, irregular sleep patterns could increase the risk of developing diabetes (23). Although obesity was more often found in the diabetics' group, it appeared to have a minor influence on the sleep pattern.

Sleep disorders, particularly insomnia, appear to have important and negative consequences $(5-7,24)$. In our study, insomnia as a disease was significantly more frequent among the diabetics, as about a third of them complained of it, while insomnia symptoms were fairly equally reported. As the data collected by the PSQI showed, there were hardly any differences in the sleep parameters (such as going out/to bed times, duration, latency), but patients suffered from less efficient and more disturbed sleep, and chose to use hypnotics more often. Nocturia, feeling too cold or too warm were the main reasons for disturbed sleep. Nocturnal pains were fairly similar among the groups, although neuropathic pain is quite an often complication of the diabetes. The PIRS confirmed much of the PSQI results, as patients again scored significantly higher than controls, this meaning that insomnia was less severe in the second group. Not surprisingly, sleep loss had more profound effects in the first group, with daytime sleepiness and fatigue affecting the individual particularly in the mental and motivational fields. Although there is consistent data pointing out that long or short sleep duration associate with diabetes $(2,22,25,26)$, and sleep duration was described as a strong predictor of glucose control through $\mathrm{HbA}_{1 \mathrm{c}}$ (2), we report no differences between patients and controls in the current study.

There are now many indications that the circadian clock plays a major role in the development of type 2 diabetes (27-30). To our knowledge it is the first time when diurnal preference was assessed in diabetic patients as a marker of the circadian timing. It has been reported that evening types suffered psychiatric disease more commonly than intermediates or morning-oriented individuals (31-33) and are more prone to substance misuse (34-36); we did find a significant link of the evening type with depression, too. As related to any of the other variables under investigation in the present study, we report no significant association with diurnal preference, but this could be due to the sample size and the way data was collected. Still, associating behaviors with biological circadian phase markers, such as melatonin and core body temperature (37), genetic polymorphisms of clock genes (38) or RNA profiling (39) may in the future provide deeper insight into the interaction of circadian timing and type 2 diabetes, as well as other endocrine 
disorders (40).

\section{Study Limitations}

As controls were not screened for impaired glucose tolerance, some cases of diabetes may have been undiagnosed. Glucose control was not monitored. Sleep and sleep loss consequences were selfassessed with psychological instruments that are not as reliable as objective measurements. Therefore, there could be over- or underestimations of the assessed variables. Moreover, we did not ascertain if insomnia appeared independently or as a consequence of diabetes.

\section{CONCLUSION}

Poor sleep, but not diurnal preference is linked with the presence of type 2 diabetes mellitus.

\section{Acknowledgements}

We would like to thank to the physicians who referred the patients to the research, particularly to Dr. Mihaela Mociran, Dr. Lavinia Pop (both Diabetologists in Baia Mare), Dr. Felicia Borz, Dr. Ligia Fanea, Dr. Cornelica Ilea, Dr. Erzsebet Hidegcuti, Dr. Coralia Ubelhart (all of them General Practitioners in Baia Mare), and all the participants taking part in the research, who kindly devoted considerable amount of their time to be tested and provide the data.

\section{References}

1.Taub LF, Redeker NS. Sleep disorders, glucose regulation, and type 2 diabetes. Biol Res Nurs. 2008;9(3):231-243.

2.Knutson KL, Ryden AM, Mander BA, Van Cauter E. Role of sleep duration and quality in the risk and severity of type 2 diabetes mellitus. Arch Intern Med. 2006; 166 (16):1768-1774.

3.Green CB, Takahashi JS, Bass J. The meter of metabolism. Cell. 2008 ;134:728-742.

4.Tuomilehto H, Peltonen M, Partinen M, Seppä J, Saaristo T, Korpi-Hyövälti E, Oksa H, Puolijoki H, Saltevo J, Vanhala M, Tuomilehto J. Sleep duration is associated with an increased risk for the prevalence of type 2 diabetes in middle-aged women The FIN-D2D survey. Sleep Medicine 2008;9(3):221-227.

5.Kawakami N, Takatsuka N, Shimizu H. Sleep Disturbance and Onset of Type 2 Diabetes. Diabetes Care. 2004;27:282-283. 6.Spiegel K. Sleep loss as a risk factor for obesity and diabetes. Int J Pediatr Obes. 2008;3 Suppl 2:27-28.

7.Spiegel K, Tasali E, Leproult R, Van Cauter E. Effects of poor and short sleep on glucose metabolism and obesity risk. Nat Rev Endocrinol. 2009;5(5):253-261.

8.Moul DE, Hall M, Pilkonis PA, Buysse DJ. Self-report measures of insomnia in adults: rationales, choices, and needs. Sleep Med Rev. 2004;8(3):177-198.

9.Smith CS, Reilly C, Midkiff K. Evaluation of three circadian rhythm questionnaires with suggestions for an improved measure of morningness. J Appl Psychol. 1989; 74 (5): 728-738.

10.Violani C, Devoto A, Lucidi F, Lombardo C, Russo PM. Validity of a Short Insomnia Questionnaire: the SDQ. Brain Res Bull 2004;63:415-421.

11.Moul D, Pilkonis P, Miewald J, Carey T, Buysse D. Preliminary study of the testretest reliability and concurrent validities of the Pittsburgh Insomnia Rating Scale (PIRS). Sleep. 2002; 25 (Abstract Supplement): A 246 - A7.

12. Buysse DJ, Reynolds CF, Monk TH, Berman S.R., Kupfer DJ. The Pittsburgh 


\section{B. Voinescu et al.}

Sleep Quality Index (PSQI): A new instrument for psychiatric research and practice. Psychiatry Research. 1989; 28 (2): 193-213.

13.Johns MW. A new method for measuring daytime sleepiness: the Epworth sleepiness scale. Sleep. 1991;14(6):540-545.

14.Smets EM, Garssen B, Bonke B, De Haes JC. The Multidimensional Fatigue Inventory (MFI) psychometric qualities of an instrument to assess fatigue. $\mathrm{J}$ Psychosom Res. 1995; 39 (3): 315-325. 15.Saunders JB, Aasland OG, Babor TF, de la Fuente JR, Grant M. Development of the Alcohol Use Disorders Identification Test (AUDIT): WHO Collaborative Project on Early Detection of Persons with Harmful Alcohol Consumption-II. Addiction. 1993; 88(6):791-804.

16.Beck AT, Steer RA, Ball R, Ranieri W. Comparison of Beck Depression Inventories -IA and -II in psychiatric outpatients. Journal of Personality Assessment. 1996; 67(3):588-597.

17.Voinescu BI. Insomnia - A Circadian Rhythm's Disturbance. Cluj-Napoca: Iuliu Hatieganu University of Medicine and Pharmacy; 2010.

18.Voinescu BI, Coogan AN, Orasan R. Psychometric Properties of the Romanian Translation of the Composite Scale of Morningness in Healthy Adults. Cognition, Brain, Behaviour: An Interdisciplinary Journal. 2010;14(1):37-46.

19.Reinert DF, Allen JP. The Alcohol Use Disorders Identification Test (AUDIT): a review of recent research. Alcohol Clin Exp Res. 2002;26(2):272-279.

20.Spiegel K, Knutson K, Leproult R, Tasali E, Van Cauter E. Sleep loss: a novel risk factor for insulin resistance and Type 2 diabetes. J Appl Physiol. 2005; 99 (5): 2008-2019.
21.Trento M, Broglio F, Riganti F, Basile M, Borgo E, Kucich C, Passera P, Tibaldi P, Tomelini M, Cavallo F, Ghigo E, Porta M. Sleep abnormalities in type 2 diabetes may be associated with glycemic control. Acta Diabetol 2008; 45(4):225-229.

22.Tasali E, Leproult R, Spiegel K. Reduced sleep duration or quality: relationships with insulin resistance and type 2 diabetes. Prog Cardiovasc Dis. 2009; 51(5):381-391.

23.Scheer FA, Hilton MF, Mantzoros CS, Shea SA. Adverse metabolic and cardiovascular consequences of circadian misalignment. Proc Natl Acad Sci U S A. 2009;106(11):4453-4458.

24.Vgontzas AN, Liao D, Pejovic S, Calhoun S, Karataraki M, Bixler EO. Insomnia with objective short sleep duration is associated with type 2 diabetes: A population-based study. Diabetes Care 2009; 32(11):1980-1985.

25.Gottlieb DJ, Punjabi NM, Newman AB, Resnick HE, Redline S, Baldwin CM, Nieto FJ. Association of Sleep Time With Diabetes Mellitus and Impaired Glucose Tolerance. Arch Intern Med. 2005; 165(8):863-867.

26.Gangwisch JE, Heymsfield SB, BodenAlbala B, Buijs RM, Kreier F, Pickering TG, Rundle AG, Zammit GK, Malaspina D. Sleep duration as a risk factor for diabetes incidence in a large U.S. sample. Sleep. 2007; 30(12):1667-1673.

27.Ando H, Takamura T, Matsuzawa-Nagata N, Shima KR, Eto T, Misu H, Shiramoto M, Tsuru T, Irie S, Fujimura A, Kaneko S. Clock gene expression in peripheral leucocytes of patients with type 2 diabetes. Diabetologia 2009; 52(2):329-335.

28.Kreier F, Kalsbeek A, Sauerwein HP, Fliers E, Romijn JA, Buijs RM. "Diabetes of the elderly" and type 2 diabetes in 
younger patients: possible role of the biological clock. Exp Gerontol. 2007;42 (12): 22-27.

29.Prasai MJ, George JT, Scott EM. Molecular clocks, type 2 diabetes and cardiovascular disease. Diab Vasc Dis Res. 2008; 5(2):89-95.

30.Scott EM, Carter AM, Grant PJ. Association between polymorphisms in the clock gene, obesity and the metabolic syndrome in man. Int J Obes (Lond). 2008; 32(4):658-662.

31.Drennan MD, Klauber MR, Kripke DF, Goyette LM. The effects of depression and age on the Horne-Ostberg morningnesseveningness score. J Affect Disord. 1991; 23(2):93-98.

32.Mansour HA, Wood J, Chowdari KV, Dayal M, Thase ME, Kupfer DJ, Monk TH, Devlin B, Nimgaonkar VL. Circadian Phase Variation in Bipolar I Disorder. Chronobiology International. 2005; 22 (3): 571-584.

33.Díaz-Morales JF, Pilar Sánchez-López M. Morningness-eveningness and anxiety among adults: A matter of sex/gender? Personality and Individual Differences. 2008;44(6):1391-1401.

34.Adan A. Chronotype and personality factors in the daily consumption of alcohol and psychostimulants. Addiction. 1994;89
(4):455-462.

35.Mecacci L, Rocchetti G. Morning and evening types: stress-related personality aspects. Personality and Individual Differences. 1998;25(3):537-542.

36.Taillard J, Philip P, Chastang JF, Diefenbach K, Bioulac B. Is self-reported morbidity related to the circadian clock? J Biol Rhythms. 2001; 16 (2): 183-190.

37.Pandi-Perumal SR, Smits M, Spence W, Srinivasan V, Cardinali DP, Lowe AD, Kayumov L. Dim light melatonin onset (DLMO): A tool for the analysis of circadian phase in human sleep and chronobiological disorders. Progress in Neuro-Psychopharmacology and Biological Psychiatry. 2007;31(1):1-11.

38.Piggins HD. Human clock genes. Ann Med. 2002;34(5):394-400.

39.Kusanagi H, Hida A, Satoh K, Echizenya M, Shimizu T, Pendergast JS, Yamazaki S, Mishima K. Expression profiles of 10 circadian clock genes in human peripheral blood mononuclear cells. Neurosci Res. 2008; 61(2):136-142.

40.Ianas O, Manda D, Dinu-Draganescu D, Calarasu R, Busu C, Vladoiu S. Circadian changes of melatonin secretion in male idiopathic infertility. Acta Endocrinologica (Buc). 2006;2(2):129-138. 
